\section{P195 RECORDING PAEDIATRIC INTERHOSPITAL TRANSFERS- AN INNOVATIVE QUALITY IMPROVEMENT PROJECT}

Cillian Lineen*, Wajida Mazher, Erica Crothers, Eoin Fitzgerald, Siobhán Gallagher, AnneMarie Murphy. University Hospital Limerick, Limerick, Ireland

10.1136/archdischild-2019-epa.550

Introduction The Department of Paediatrics, University Hospital Limerick caters for a catchment area of over 100,000 children less than 16 years of age.

Approximately 160 children (mostly critically ill) require direct interhospital Transfer to the Tertiary level centres in any 12 month period.

In our unit, in the past we kept records of interhospital Patient transfers in a notebook affectionately termed 'The Transfer Out book'. These cases are then discussed at our quarterly Morbidity and Mortality meeting.

The details provided in this book for each case were often incomplete.

Aim Our objective was to create a template 'transfer-out' page that records necessary details of Interhospital Paediatric patient transfers- a proforma using 'tick boxes' to make the process quick, easy yet thorough.

Results The design of the template incorporated feedback from Medical and Nursing staff, who previously had documented details of patient transfers informally in a notebook.

The main details documented are reason for transfer, level of ventilatory support during transfer, mode of transport, accompanying healthcare professionals, in addition to accepting hospital and team. (See attached document).

Responsibility for documenting these details lies with the Paediatric medical team organising the patient transfer.

Patient outcomes and issues during transfer are not recorded in this format but are discussed when the cases are presented at our Morbidity and Mortality meetings.

The template was bound into an easy-to-read and easy-tofill out book containing 350 pages of 100 gsm cream paper. The book is stored in our Paediatric High Dependency Unit alongside the healthcare records of current inpatients.

The book, now affectionately called 'The Navy Bible' was well received with staff reporting that the layout is straightforward making logging a transfer succinct yet comprehensive.

Conclusions Keeping accurate records is fundamental to healthcare. The main advantage of our new Interhospital transfer book is improved documentation of transfers. This will not only enable our Department to reflect on the care we provide for our patients, but to analyse where we can improve our own services. The electronic healthcare record is the way of the future but in the meantime our quality improvement project has benefited our department.

\section{P196 EVALUATION OF LOCAL CARDIOLOGY SERVICES FOR INFANTS AND NEONATES WITH SUSPECTED CONGENITAL HEART DISEASE}

Muhammad Shoaib Iqbal*, Yusra Abdulrab, Rizwan Khan, Sanjay raina. Princess Alexandra Hospital, Harlow, UK

10.1136/archdischild-2019-epa.551

Background Murmur is one of the commonest reasons for referral to paediatric cardiologists. This has caused a long waiting time for clinic and increased parental anxiety.
Objectives To assess the local cardiology services for suspected congenital heart diseases in neonates and infants at Princess Alexandra Hospital Harlow, Essex, UK

Methods Retrospective data was collected from period of May 2018 to November 2018 from online database and patient notes including all the neonates and infants referred and seen in paediatric cardiology clinic during this period.

Results Total 30 patients were studied. 56.6\% were females and $43.3 \%$ were males. The mean waiting time was 4 months. Commonest reason for referral was heart murmur in $40 \%$ patients and $2^{\text {nd }}$ common reason was family history of congenital heart diseases in 30\%. Echocardiogram was normal in 20\% and the commonest defects were VSD and ASD $20 \%$ each. Amongst those having heart murmurs 16.6\% were normal and discharged, $8.3 \%$ had PFO and discharged and $8.3 \%$ had tiny PDA. Our local referral pathways recommend discussion with consultant before referral but only $10 \%$ patients were discussed with the consultant and $83.3 \%$ had no documentation regarding discussion with consultant. In only 105 of referrals the local referral pathway was followed.

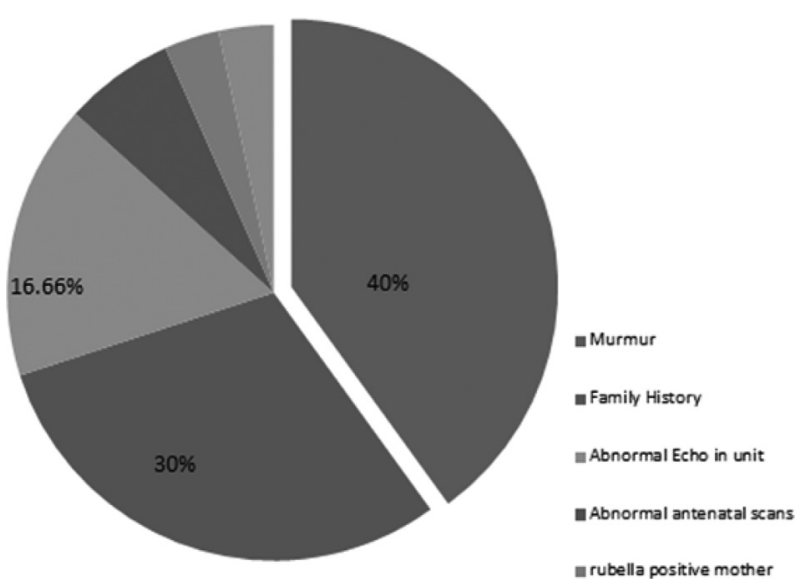

Cleft palate

\section{Abstract P196 Figure 1}

Conclusion The commonest reason for referral to cardiology clinic for infants and neonates is heart murmur. If we develop our local murmur guidelines then it will be easy to decide whom we need to see in cardiology clinic and this can avoid un-necessary cardiology clinic referrals without missing the pathologies. We intend to develop our local murmur guidelines as a next step to quality improvement project.

\section{Recommendations}

1. Create awareness amongst doctors about cardiology clinic referral form for neonates and infants with suspected congenital heart disease through teaching sessions and during induction of new doctors.

2. The referral form should be duly signed by the consultant making referral and the cardiology consultant accepting and the signed form should be attached in the patient notes in correspondence.

3. We need to develop out local cardiology guidelines for neonates and infants with heart murmur and/or suspected congenital heart disease so that un-necessary referrals can be avoided without missing the congenital heart defects. 